\title{
POLG1 p.R722H mutation associated with multiple mtDNA deletions and a neurological phenotype
}

\author{
Tuomas Komulainen 1,6, Reetta Hinttala2,6, Mikko Kärppä2,6, Leila Pajunen33, Saara Finnilä2,6, Hannu Tuominen4, \\ Heikki Rantala1, IImo Hassinen5, Kari Majamaa*2,6 and Johanna Uusimaa1,6
}

\begin{abstract}
Background: The c.2447G > A (p.R722H) mutation in the gene POLG1 of the catalytic subunit of human mitochondrial polymerase gamma has been previously found in a few occasions but its pathogenicity has remained uncertain. We set out to ascertain its contribution to neuromuscular disease.

Methods: Probands from two families with probable mitochondrial disease were examined clinically, muscle and buccal epithelial DNA were analyzed for mtDNA deletions, and the POLG1, POLG2, ANT1 and Twinkle genes were sequenced.
\end{abstract}

Results: An adult proband presented with progressive external ophthalmoplegia, sensorineural hearing impairment, diabetes mellitus, dysphagia, a limb myopathy and dementia. Brain MRI showed central and cortical atrophy, and 18Fdeoxyglucose PET revealed reduced glucose uptake. Histochemical analysis of muscle disclosed ragged red fibers and cytochrome c oxidase-negative fibers. Electron microscopy showed subsarcolemmal aggregates of morphologically normal mitochondria. Multiple mtDNA deletions were found in the muscle, and sequencing of the POLG1 gene revealed a homozygous c. $2447 \mathrm{G}>\mathrm{A}$ (p.R722H) mutation. His two siblings were also homozygous with respect to the p.R722 H mutation and presented with dementia and sensorineural hearing impairment. In another family the p.R722 H mutation was found as compound heterozygosity with the common p.W748S mutation in two siblings with mental retardation, ptosis, epilepsy and psychiatric symptoms. The estimated carrier frequency of the p.R722H mutation was 1:135 in the Finnish population. No mutations in POLG2, ANT1 and Twinkle genes were found. Analysis of the POLG1 sequence by homology modeling supported the notion that the p.R722H mutation is pathogenic.

Conclusions: The recessive c. $2447 \mathrm{G}>\mathrm{A}$ (p.R722H) mutation in the linker region of the POLG1 gene is pathogenic for multiple mtDNA deletions in muscle and is associated with a late-onset neurological phenotype as a homozygous state. The onset of the disease can be earlier in compound heterozygotes.

\section{Background}

DNA polymerase $\gamma($ pol $\gamma)$ is the only polymerase responsible for the synthesis and repair of mitochondrial DNA in mammalian cells $[1,2]$. The human mitochondrial DNA polymerase is a $195 \mathrm{kDa}$ heterotrimer consisting of a $140 \mathrm{kDa}$ catalytic subunit (pol $\gamma \mathrm{A}$ ) and two identical 55 $\mathrm{kDa}$ accessory subunits (pol $\gamma \mathrm{B})$ [3]. The C-terminus of the catalytic subunit PolyA is the pol domain, which is responsible for the polymerase function, while the N-terminus is responsible for exonuclease activity and proofreading of the mitochondrial DNA (mtDNA). The linker

*Correspondence: kari.majamaa@oulu.fi

2 Department of Neurology, University of Oulu, Box 5000, FIN-90014, University of Oulu, Oulu, Finland

Full list of author information is available at the end of the article mediates a focal contact with the dimeric accessory subunit [4]. PolyA is encoded by the POLG1 gene [RefSeq:NM_002693].

Numerous mutations in the POLG1 have been described recently, with various clinical presentations $[5,6]$ including autosomal dominant and autosomal recessive familial external ophthalmoplegia (PEO) [7-10], autosomal recessive sensory ataxic neuropathy with dysarthria and ophthalmoplegia (SANDO) [11], a mixed sensory and cerebellar ataxic syndrome with epilepsy $[12,13]$, parkinsonism $[14,15]$ and Alpers' hepatocerebral syndrome [16-19]. Other conditions associated with POLG1 mutations include male subfertility, premature 
menopause and cataracts [15,20]. POLG1 mutations can cause deletions or depletion in mtDNA [16,21-23].

We studied here the molecular etiology of a clinically probable mitochondrial disease in five patients from two Finnish families. In one family (Family A), an adult patient presented with progressive external ophthalmoplegia, sensorineural hearing impairment, diabetes mellitus and dementia. In the other family (Family B), a child presented with mental retardation, ptosis, epilepsy and psychiatric problems.

\section{Methods}

Patients

Patient A1 is an 83-year-old man with sensorineural hearing impairment, type 2 diabetes mellitus, dysphagia and external ophthalmoplegia. A hearing aid had been provided at age 72 years. At age 77 years, MMSE score was 19 and a neuropsychological examination revealed a mixed-type dementia. Neurological examination at age 83 years revealed external ophthalmoplegia and bilateral ptosis. Tendon reflexes in the lower limbs were absent and muscles were scanty, but muscle strength was normal. The MMSE score was 8 . His ambulatory capacity was normal, but he needed help in most of his daily activities due to dementia.

Laboratory investigations including blood lactate, pyruvate and creatine kinase were normal, as were the EEG recording and electrophysiological examination of the peripheral nerves. Brain MRI demonstrated moderate cortical and central atrophy (Figure 1), including hippocampal atrophy. Periventricular hyperintensities and a left basal ganglia infarct were also found. PET performed with ${ }^{18} \mathrm{~F}$-deoxyglucose (FDG-PET) showed a reduction in glucose uptake in the frontal, frontotemporal and frontoparietal regions (data not shown). Atrophic angular, mostly type 2 muscle fibers were seen in a histological examination of the left quadriceps muscle. Histochemical analysis disclosed ragged red fibers and cytochrome oxi-

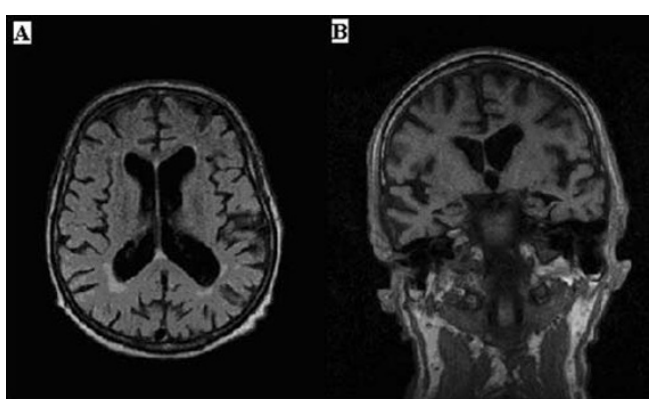

Figure 1 The brain MRI of patient A1. Axial (A) and coronal (B) MRI images of the brain of patient $A 1$ demonstrate moderate central and cortical atrophy. dase-negative fibers. Electron microscopy showed subsarcolemmal aggregates of morphologically normal mitochondria (Table 1).

Patient A2 is the younger sister of patient A1. She is a 78-year-old woman with a history of hypertension, sensorineural hearing impairment requiring a hearing aid, hypercholesterolemia, bilateral cataract and chronic gastritis. She had been complaining of occasional headaches since the age of 30 years. A neurological examination had been performed at age 72 years on account of memory impairment. There were no focal findings in the neurological examination. Brain CT revealed cortical atrophy and one frontal lacunar infarct. The MMSE score was 26 and the score declined to 20 during the three subsequent years. Her dementia, which involved behavioural changes including aggressive symptoms and paranoid delusions, was regarded as being of an Alzheimer-like type, and cholinergic therapy was introduced. Blood lactate was slightly elevated $(2.6 \mathrm{mmol} / \mathrm{l}$, normal range $0.33-1.33$ $\mathrm{mmol} / \mathrm{l})$, but blood pyruvate was normal $(71 \mu \mathrm{mol} / \mathrm{l}$, normal range $30-80 \mu \mathrm{mol} / \mathrm{l})$, so that the lactate-pyruvate ratio was increased $(37$, normal $<20)$. The remaining laboratory tests were normal.

Patient A3 is the elder sister of patient A1. She is an 86 year-old woman with a clinical history of hypertension, type 2 diabetes mellitus, sensorineural hearing impairment, osteoarthritis, hypercholesterolemia and coronary heart disease. She had a mild left motor hemiparesis at the age of 74 years due to a lacunar brain infarct. Memory impairment appeared and mild dementia was diagnosed by a general practitioner, with CERAD and an MMSE score of 22. There were no focal neurological signs except for an absence of tendon reflexes. Brain CT revealed lacunar changes in the right hemisphere but no atrophic findings.

Patient B1 is the first child of healthy non-consanguineous parents. She was born after an uncomplicated fullterm pregnancy and normal delivery. The perinatal period was uneventful and control examinations in early childhood did not reveal any abnormalities in psychomotor development, growth or hearing except for slight visual impairment. Learning difficulties were noticed

Table 1: Summary of the histological and histochemical findings of the muscle biopsy of patient A1.

\begin{tabular}{ll}
\hline Histological findings & Light microsopy: Atrophic, \\
& angular muscle fibers \\
& Electron microscopy: \\
& subsarcolemmal aggregates, \\
morphologically normal & mitochondria \\
Histochemical findings & Ragged red fibers \\
& Cytochrome coxidase \\
& negative fibers \\
\hline
\end{tabular}


after attending school for some time and she was transferred to a special class for children with learning disabilities. Seizures occurred at age 11 years, and focal generalized epilepsy was diagnosed. Her EEG was abnormal, showing focal bilateral frontotemporal irritation with secondary generalization, but a brain CT was normal. No local neurological defects were found in the follow-up clinical examination except for mild bilateral ptosis. Pubertal development was normal and she has normal menstruations. However, she gradually developed behavioral and psychiatric problems, including depression, aggressivity and suicidality and had some psychotic episodes needing hospitalization. She has no somatic health problems except for occasional cardiac arrhythmia and mild obesity. At present she is a 22-year-old woman learning to live independently, but still needs support in her daily life due to mild mental retardation and some behavioral problems.

Patient B2 is the younger sister of patient B1. She was born after a normal full-term pregnancy and delivery. Early psychomotor development was normal, but mild mental retardation was diagnosed before school age. She attended a special school for children with learning disabilities. Her pubertal development was normal, but she is mildly obese and has a mild bilateral ptosis. Like her elder sister, she has psychiatric problems, including depression, aggressivity and suicidality. At present she is a 17 -year-old young woman living in a residential school for people with learning disabilities.

\section{Clinical evaluation}

Patients A1, A3, B1 and B2 were evaluated clinically by means of a neurologic examination, laboratory tests and long PCR of buccal DNA for possible mtDNA deletions. The medical charts of patient A2 were reviewed. Fourteen members of family A (Figure 2) were interviewed using a questionnaire.

\section{Molecular methods}

Total genomic DNA was extracted from blood, muscle and buccal smear samples using the standard sodium dodecyl sulphate-proteinase $\mathrm{K}$ method or a QIAamp Blood Kit (Qiagen, Hilden, Germany) according to the manufacturer's instructions.

\section{Detection of mtDNA deletions}

MtDNA deletions were analyzed by long PCR (XL-PCR) carried out using the Expand Long Template PCR System kit (Boehringer Mannheim, Mannheim, Germany) as described earlier [24].

\section{Analysis of the POLG1, POLG2, ANT1 and Twinkle genes}

Blood DNA was used as a template to amplify and sequence the 23 coding exons of the POLG1 gene [RefSeq:NM_002693] in the probands (patients A1 and B1) by automated sequencing (ABI PRISM ${ }^{\mathrm{m}} 377$ Sequencer) using the Dye Terminator Cycle Sequencing Ready Kit (Perkin Elmer, Foster City, CA, U.S.A.) after treatment with exonuclease I and shrimp alkaline phosphatase. The entire coding sequence of the POLG2, ANT1 and Twinkle genes were also determined.

Southern blot analysis was carried out using a biotinlabeled probe. Total genomic DNA extract was digested with FastDigest PvuII (Fermentas, Burlington, ON, Canada). The mtDNA probe was amplified with PCR between nucleotide positions 15714 and 725 to cover the D-loop area, which is rarely involved in mtDNA deletions. PCR reaction included biotin-16-dUTP (Roche, Mannheim, Germany). The nylon membrane filter (Millipore, Billerica, ME, U.S.A.) was prehybridized, hybridized with the probe, washed and incubated with Odyssey Blocking Buffer (LI-COR Biosciences, Lincoln, NE, U.S.A.) and Streptavidin-IRDye $800 \mathrm{CW}$ conjugate (LICOR Biosciences). The blot was scanned with Odyssey Infrared Imaging System (LI-COR Biosciences).

\section{Sequence analysis and molecular modeling}

Secondary structure of pol $\gamma \mathrm{A}$ was analyzed with the Jpred3 server [25]. Sequence alignment of DNA polymerase $\gamma \mathrm{A}$ of Homo sapiens (human), Pan troglodytes (chimpanzee), Canis lupus familiaris (dog), Mus musculus (house mouse), Rattus norvegicus (rat), Gallus gallus (chicken), Danio rerio (zebrafish) and Drosophila melanogaster (fruit fly) was carried out with the ClustalW program.

Molecular modeling of the wild-type or R722H mutation-carrying DNA polymerase- $\gamma \mathrm{A}$ protein was performed with the Modeller (v. 8.2) [26] program by using the 3-D structure of the Klenow fragment of Escherichia coli DNA polymerase I (1kln.pdb) as a template, and the results were visualized with the MOLMOL program [27].

\section{Detection of the POLG1 c.2447G >A (p.R722H) mutation}

The POLG1 c.2447G>A (p.R722H) mutation was detected by restriction fragment analysis using a mismatch primer that creates a restriction site for MlsI (BalII) in the presence of the mutation. The mismatch primer was designed in a forward direction with the sequence 5'-TGTGTGGCCCTCACAGACTGGCC-3' (mismatch base underlined). The sequence of the reverse primer was 5'-TCAGGTGTGTCACTCTGAAGG-3'. Template DNA was amplified by PCR, digested and the products electrophoresed on a 3\% MetaPhor (Cambrex Bio Science Rockland, Inc., Rockland, ME, U.S.A.) gel stained with ethidium bromide. The wild-type allele yields a 221-bp band and the mutant allele a 183-bp band.

Detection of the POLG1 c.2243G >C (p.W748S) mutation

Allele-specific amplification was used to verify the c.2243G $>$ C (p.W748S) mutation in the blood DNA of 


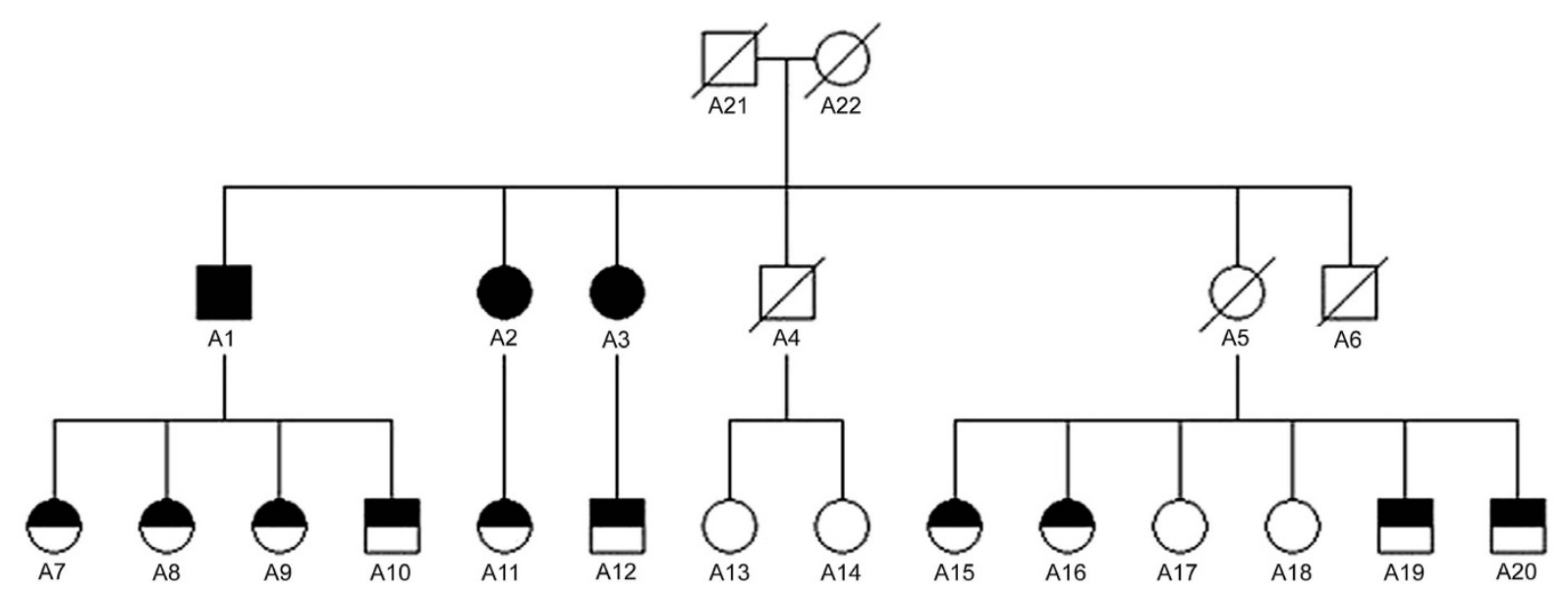

Figure 2 Pedigree of family A. Fully shaded squares (men) and circles (women) denote homozygous c.2447G>A (p.R722H) mutations in the POLG1 gene and half-shaded symbols heterozygosity.

patients B1 and B2 and their mother. The primers, containing a locked nucleic acid (LNA) nucleoside base at the 3 ' end (Proligo LLC, Paris, France), were designed to anneal with either the wild-type sequence or the sequence containing the mutation [28]. The sequence of the LNA Polg14F/G primer was 5'-GGACATCCCTGGCTGCT+G-3' and of the LNA Polg14F/C 5'-GGACATCCCTGGCTGCT $+C-3$ '. The sequence of the reverse primer was 5'-TCAGGTGTGTCACTCTGAAGG-3'.

\section{Ethical considerations}

The study protocol has been approved by Ethical Committee of Faculty of Medicine, University of Oulu and is in compliance with the Helsinki Declaration. Written informed consent is given by all patients or their surrogates prior to the study.

\section{Results}

\section{Clinical findings}

Clinical examination of patient $\mathrm{A} 1$ and patient $\mathrm{A} 3$ and the review of the medical files of patient A2 revealed dementia, sensorineural hearing impairment, progressive external ophthalmoplegia and ptosis. The blood lactate/ pyruvate ratio was elevated in patient A2, but not in patients $\mathrm{A} 1$ and $\mathrm{A} 3$, and the cerebral glucose metabolism of patient A1 was reduced to $20-30 \%$. The brain MRI of patient A1 (Figure 1) showed moderate central and cortical atrophy, while that of patient A2 revealed cortical atrophy and one frontal lacunar infarct. A summary of the medical histories of ten POLG1 p.R722H mutation carriers, five deceased individuals and four non-carriers in the family A is presented in Table 2.

Patient B1 presented with mental retardation, psychiatric symptoms, mild bilateral ptosis and epilepsy, while her sister (patient B2) had mental retardation, psychiatric symptoms and mild bilateral ptosis, but no epilepsy. Their mother had a history of mitral valve insufficiency, which was operated on about three years ago, chronic atrial fibrillation, for which she receives permanent anticoagulant therapy, cognitive impairment and impaired hearing, but no localizing neurological symptoms. Her MMSE score was 27. The blood lactate/pyruvate ratios of patients B1 and B2 and their mother were normal. Medical history of the father was not available.

\section{Molecular genetics}

Long PCR of the muscle DNA of patient A1 showed multiple mtDNA deletions (Figure 3), and subsequent sequencing of the entire POLG1 gene revealed a homozygous c. $2447 \mathrm{G}>\mathrm{A}$ (p.R722H) transition in exon 13. Long PCR of the muscle of age-matched controls showed deletions in minor extent, but no deletions were detected with Southern blot analysis (Figure 4). The homozygous POLG1 p.R722H mutation of patient A1 was also found in patients A2 and A3 (Figure 5), but no mtDNA deletions were detected in the buccal or blood DNA of these patients (data not shown). Muscle DNA was not available for analysis from patients A2 and A3. No mutations were found in the POLG2, ANT1 and Twinkle genes analyzed from blood DNA of patients A1 and A2.

A heterozygous p.R722H mutation was found in 10 out of 17 members of family $\mathrm{A}$, and four members were 
Table 2: Summary of the medical histories of members of family A with p.R722H mutation in POLG1.

\begin{tabular}{|c|c|}
\hline $\begin{array}{l}\text { Family member } \\
\text { code }\end{array}$ & Clinical manifestation \\
\hline \multicolumn{2}{|l|}{$\begin{array}{l}\text { p.R722H } \\
\text { homozygotes }\end{array}$} \\
\hline Patient A1 & $\begin{array}{l}\text { Severe dementia, sensorineural hearing } \\
\text { impairment, diabetes mellitus, PEO, } \\
\text { dysphagia, neuropathic pain in the legs }\end{array}$ \\
\hline Patient A2 & $\begin{array}{l}\text { Moderate dementia, sensorineural } \\
\text { hearing impairment, occasional } \\
\text { headaches, cataract }\end{array}$ \\
\hline Patient A3 & $\begin{array}{l}\text { Mild dementia, sensorineural hearing } \\
\text { impairment, diabetes mellitus, } \\
\text { hypertension, coronary heart disease, } \\
\text { areflexia due to diabetic neuropathy }\end{array}$ \\
\hline \multicolumn{2}{|l|}{$\begin{array}{l}\text { Carriers of } \\
\text { p.R722H }\end{array}$} \\
\hline A7 & $\begin{array}{l}\text { Diabetes mellitus, hypothyreosis, } \\
\text { cerebral infarction, hypertension, } \\
\text { hypercholesterolemia, learning } \\
\text { difficulties }\end{array}$ \\
\hline A8 & $\begin{array}{l}\text { Transient hypertension, benign cardiac } \\
\text { arrhythmias, fertility problems }\end{array}$ \\
\hline A9 & $\begin{array}{l}\text { Hypothyreosis, gestational diabetes } \\
\text { mellitus }\end{array}$ \\
\hline A10 & Mental retardation \\
\hline A11 & $\begin{array}{l}\text { Premature puberty, short stature, fertility } \\
\text { problems, gestational diabetes mellitus }\end{array}$ \\
\hline $\mathrm{A} 12$ & Tinnitus, benign cardiac arrhythmias \\
\hline A15 & $\begin{array}{l}\text { Cataract, balance disturbances, retinal } \\
\text { rupture, tinnitus, unilateral deafness }\end{array}$ \\
\hline A16 & $\begin{array}{l}\text { Coronary heart disease, delayed puberty, } \\
\text { sensorineural hearing loss }\end{array}$ \\
\hline A19 & $\begin{array}{l}\text { Delayed puberty, hypogonadism, } \\
\text { transient vertigo, visual field defect }\end{array}$ \\
\hline A20 & Healthy \\
\hline
\end{tabular}

\section{Deceased}

individuals of

unknown

mutation status
Dementia, coronary heart disease, diabetes mellitus, rheumatoid arthritis, operated for colon cancer

A5
Diabetes mellitus, bradycardia, sensorineural hearing loss, coronary heart disease

Psychiatric problems, sudden death from intracerebral haemorrhage
Table 2: Summary of the medical histories of members of family A with p.R722H mutation in POLG1. (Continued)

\begin{tabular}{ll}
\hline A21 & $\begin{array}{l}\text { Impaired memory, sudden death from } \\
\text { cerebral infarct } \\
\text { Dementia, hemiplegia progressing to } \\
\text { diplegia, diabetes mellitus }\end{array}$ \\
\hline Non-carriers & \\
\hline A13 & $\begin{array}{l}\text { Hypertension, distal sensory impairment } \\
\text { in the hand } \\
\text { Hypertension } \\
\text { A17 }\end{array}$ \\
& $\begin{array}{l}\text { Unilateral hearing loss due to chronic } \\
\text { secretory otitis, benign cardiac } \\
\text { arrhythmia } \\
\text { A18 }\end{array}$ \\
\hline
\end{tabular}

homozygous with respect to the wild type (Figure 2). There were also five deceased individuals in this family that could be evaluated. Subject A5 had been an obligatory carrier and A21 and A22 had been carriers, or else one of them could have had a homozygous mutation, and therefore subject A4 could have been either a carrier or non-carrier of the mutation.

Patient B1 and patient B2 were heterozygous with respect to c.2447G>A (p.R722H) and, interestingly, POLG1 sequencing also revealed the c.2243G $>\mathrm{C}$ (p.W748S) mutation and p.E1143G polymorphism in patient B1 (Figure 5 and 6). POLG1 of patient B2 was not sequenced. Their mother harbored heterozygous p.W748S (Figure 5 and 6), but no DNA was available for analysis from the father or other relatives. Long PCR of buccal DNA did not show any deletions in the mtDNA of patient B1. Three samples from 403 anonymous blood donors harbored the heterozygous c.2447G>A (p.R722H), suggesting a carrier frequency of 1:135 in the population.

\section{Sequence analysis and molecular modeling}

Although the p.R722H and p.W748S mutations analyzed in this study are located in the spacer region of pol $\gamma \mathrm{A}$, they occur in an evolutionally conserved domain as depicted in Figure 7. The p.W748 is highly conserved, but p.R722 is not so well conserved even amongst mammals. The PredictProtein and Jpred3 programs do not predict major changes in the secondary structure (data not shown). The tertiary structure on the basis of crystal diffractometric data for the A-type DNA polymerases is known only for Escherichia coli POL1 Klenow fragment and bacteriophage T7. Alignment of human pol $\gamma$ A with E. coli Klenow fragment of pol 1 identifies a loosely homologous 701-724 region of pol $\gamma \mathrm{A}$. The corresponding region of pol 1 around p.R631 is situated in a crevice 


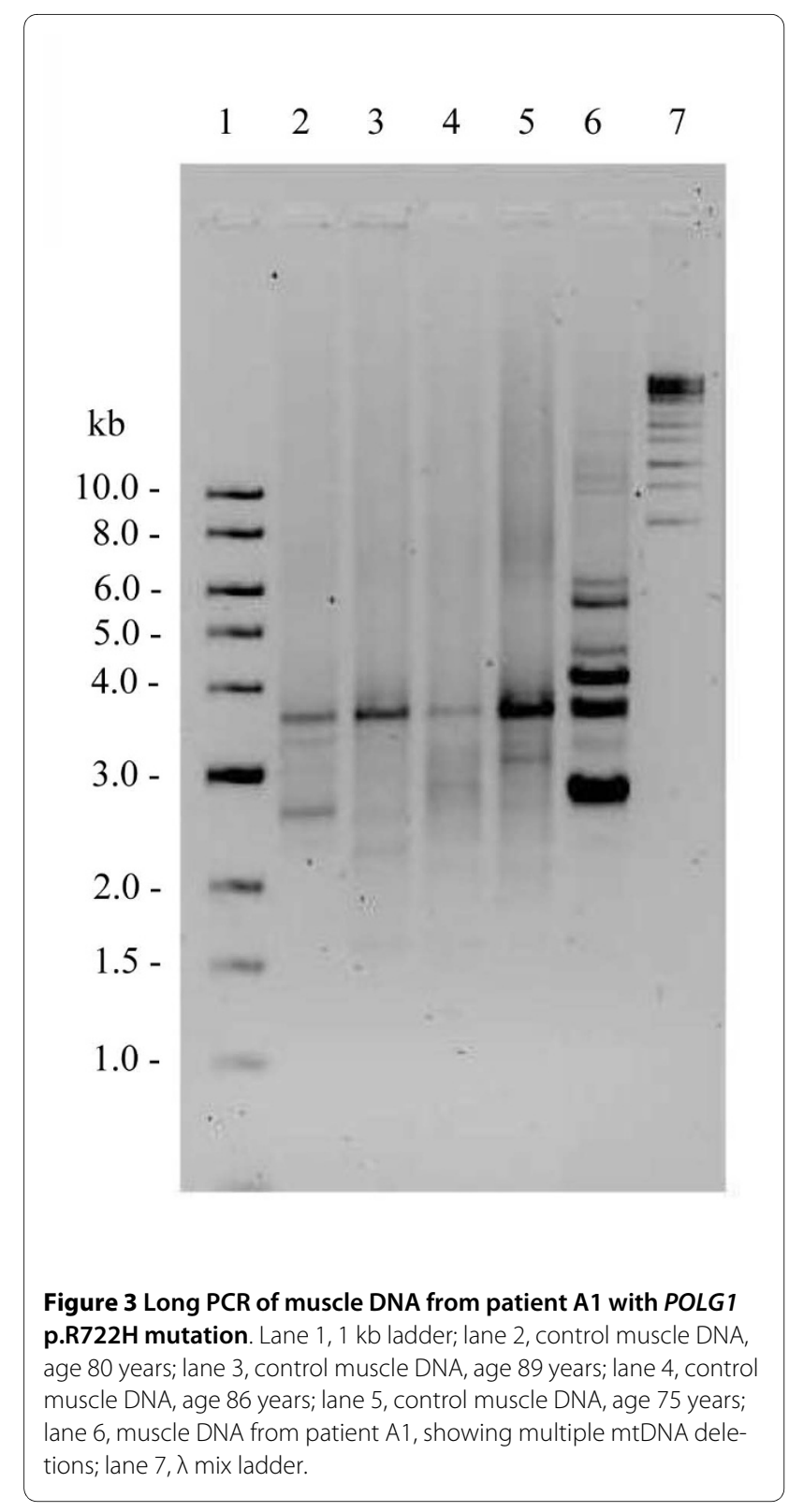

being in close interaction of DNA strand in the co-crystallized $1 \mathrm{kln}$.pdb. This region was used as template for homology modeling of pol $\gamma \mathrm{A}$. This puts the p.R722H mutation in a helical region and the p.W748S in a more flexible coil region without major effect on the secondary or tertiary structure (Figure 8).

\section{Discussion}

Heterozygous POLG1 p.R722H mutations have previously been reported in two patients with Parkinson's disease and in one control, with no difference in mutation frequencies between these groups [14]. In our study, patient A1 with the homozygous POLG1 p.R722H mutation presented with dementia and sensorineural hearing impairment together with progressive external ophthal-

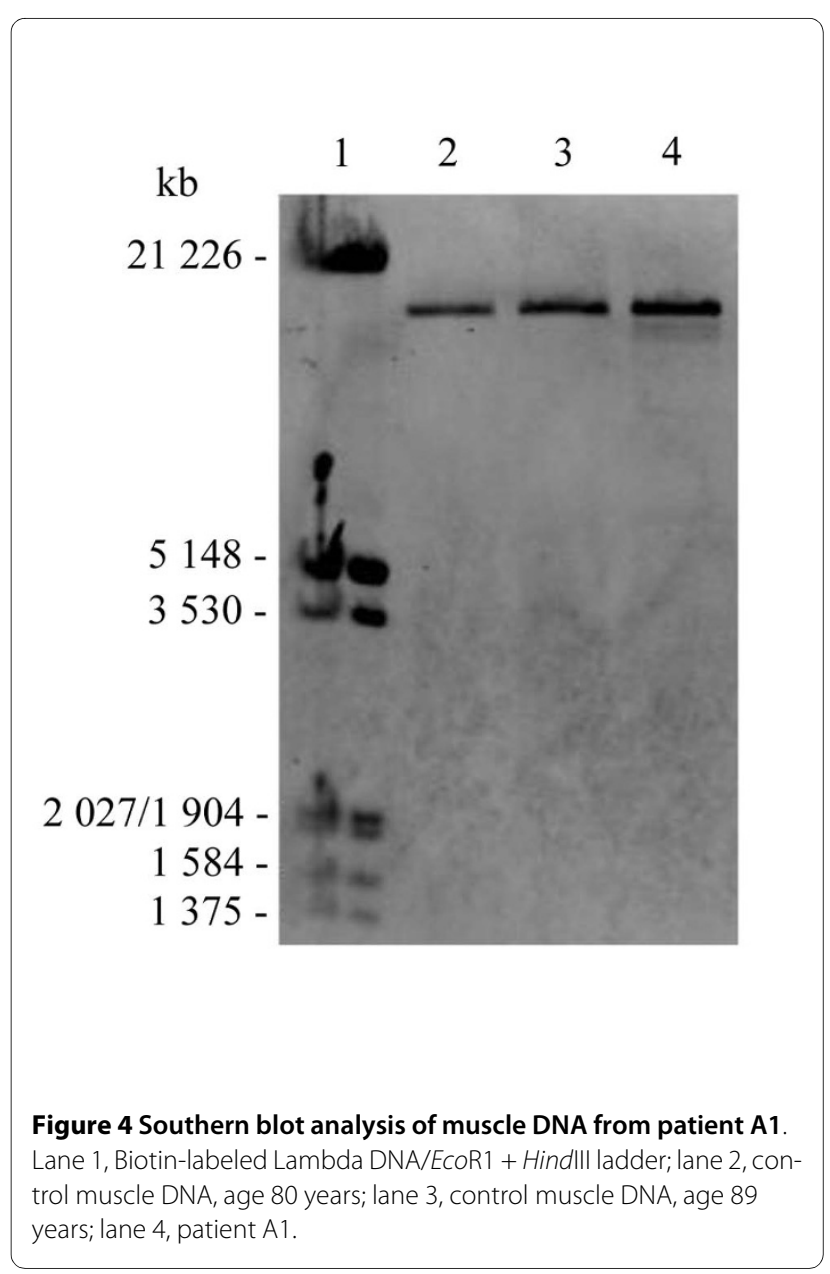

moplegia, diabetes mellitus, dysphagia and neuropathic pain in legs. Long PCR and Southern blotting revealed multiple mtDNA deletions (Figure 3 and 4), which have also been reported to be caused by several other POLG1 mutations $[7,12,13]$. Long PCR of the muscle DNA of

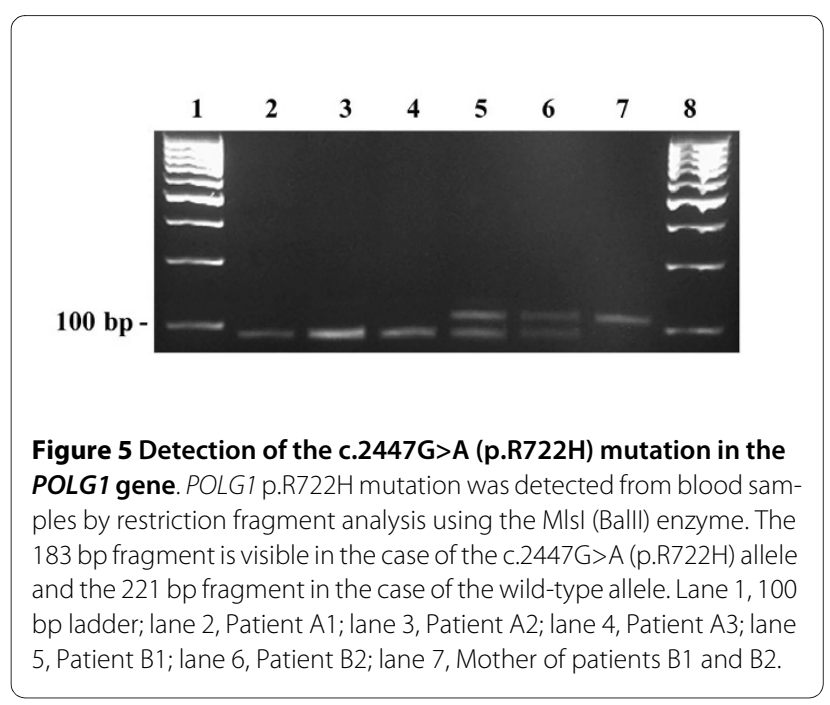




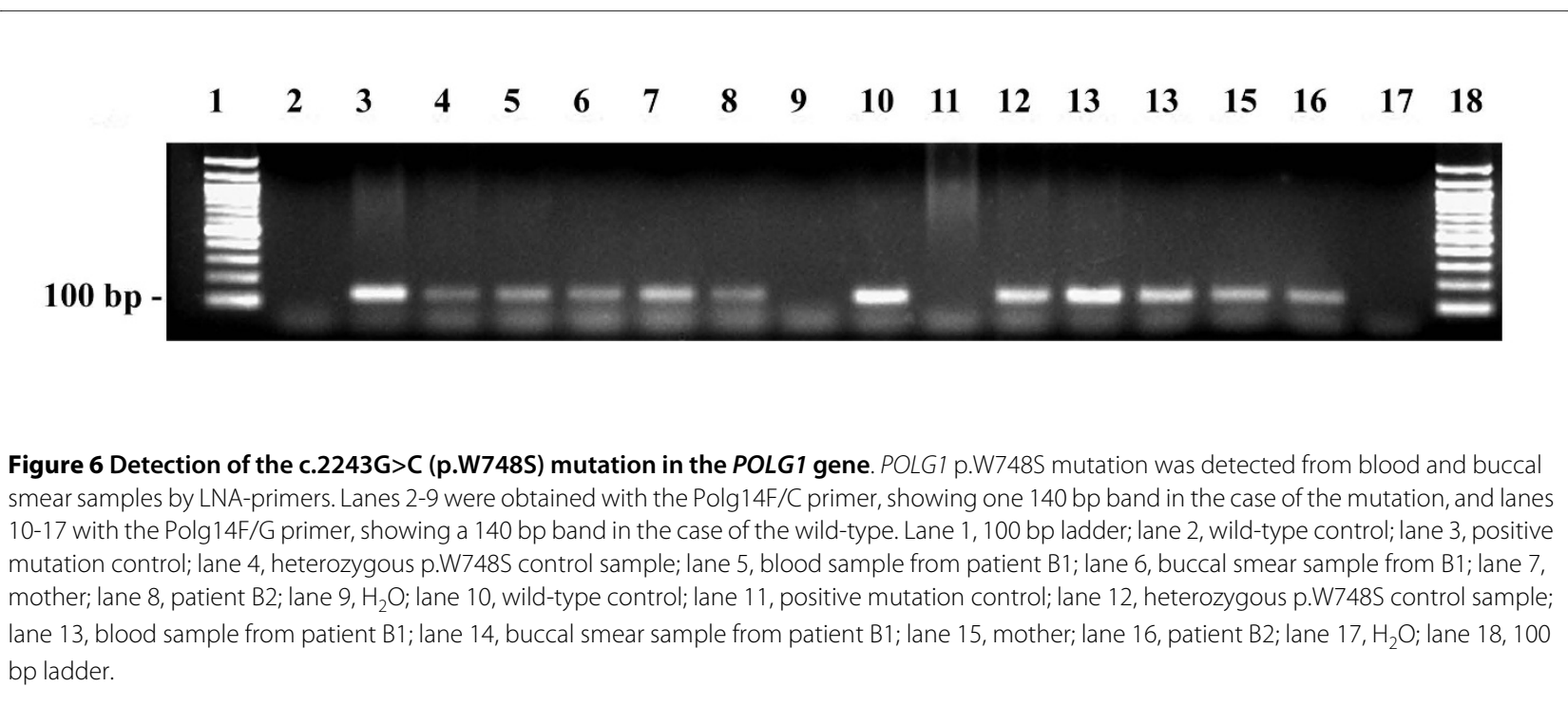

healthy control samples showed also accumulation of mtDNA deletions, but in obviously minor extent. These deletions are likely due to the aging process and the pattern of deletions is different from the deletions of the patient A1. Long PCR did not show any intact mtDNA in control samples as this method favors the amplification of shorter DNA fragments. On the other hand, Southern blot analysis showed the intact mtDNA, but did not detect deletions in the muscle DNA of control samples.

This combination of multiple mtDNA deletions, multiple neurological and endocrinological symptoms and histochemical findings, including ragged red fibers and COX-negative muscle fibers, suggests a mitochondrial origin for the disease. The clinical features also resemble those reported to be typical of POLG1 mutations $[3,5,6]$. It has been shown in a large cohort of POLG1 patients that ptosis and PEO usually presented in teenage years or adult life and additional features included a limb myopathy, ataxia, a peripheral neuropathy or dysphagia, diabetes, deafness and dementia [5]. Our patient A1 manifested with all these typical features associated with POLG1 mutations. Two sisters of patient A1 also had the homozygous p.R722H mutation and both presented with dementia and sensorineural hearing impairment. Thus, dementia and sensorineural hearing impairment segregated consistently with the mutation.

We also described the compound POLG1 p.R722H + p.W748S mutations in two siblings with mental retardation. The spectrum of clinical findings caused by the p.W748S mutation is wide, and it has been found as a heterozygous mutation compounded with other heterozygous POLG1 mutations [5,13,18,29]. Mitochon-

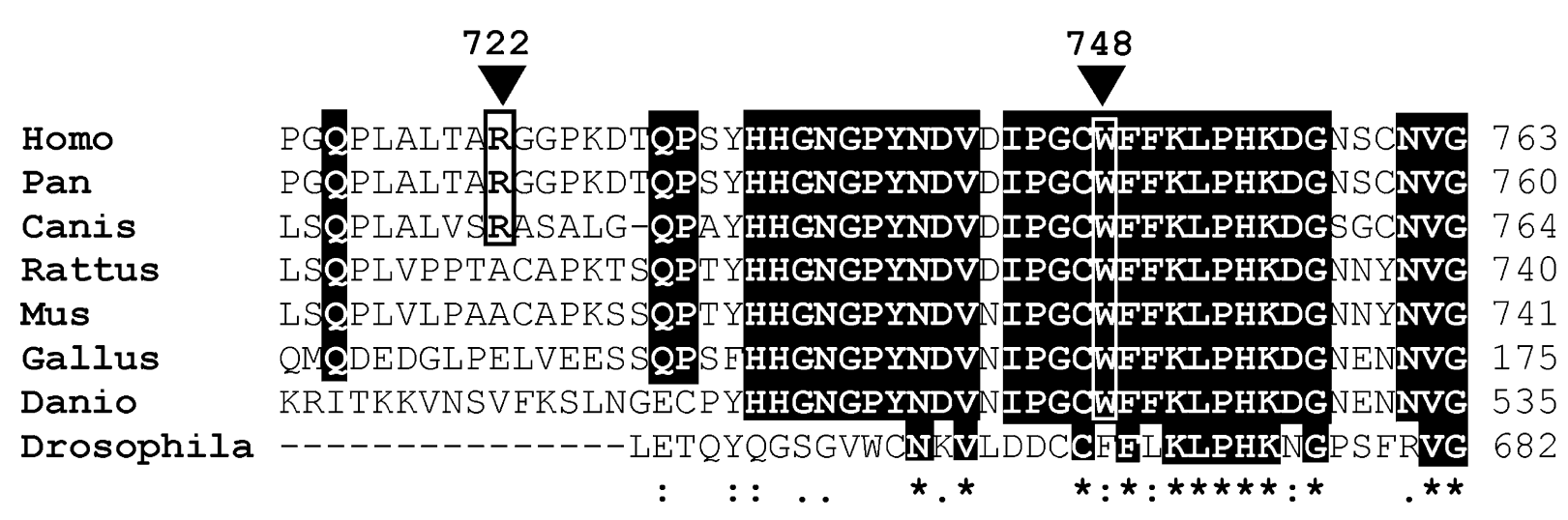

Figure 7 Sequence alignment of part of the spacer regions of DNA polymerase $\mathbf{y A}$. The mutation sites p.R722H and p.W748S are marked with arrowheads. The sequences (and accession numbers) are: human [RefSeq:NP_001119603.1], Pan troglodytes [RefSeq:XP_523149.2], Canis familaris [RefSeq:XP_545850.2], Rattus Norwegicus [RefSeq:NP_445980.1], Mus musculus [GenBank:AAA98977.1], Gallus gallus [GenBank:AAC60018.1], Danio rerio [RefSeq:XP_001921130.1] Drosophila melanogaster [GenBank:AAF53338.1]. 


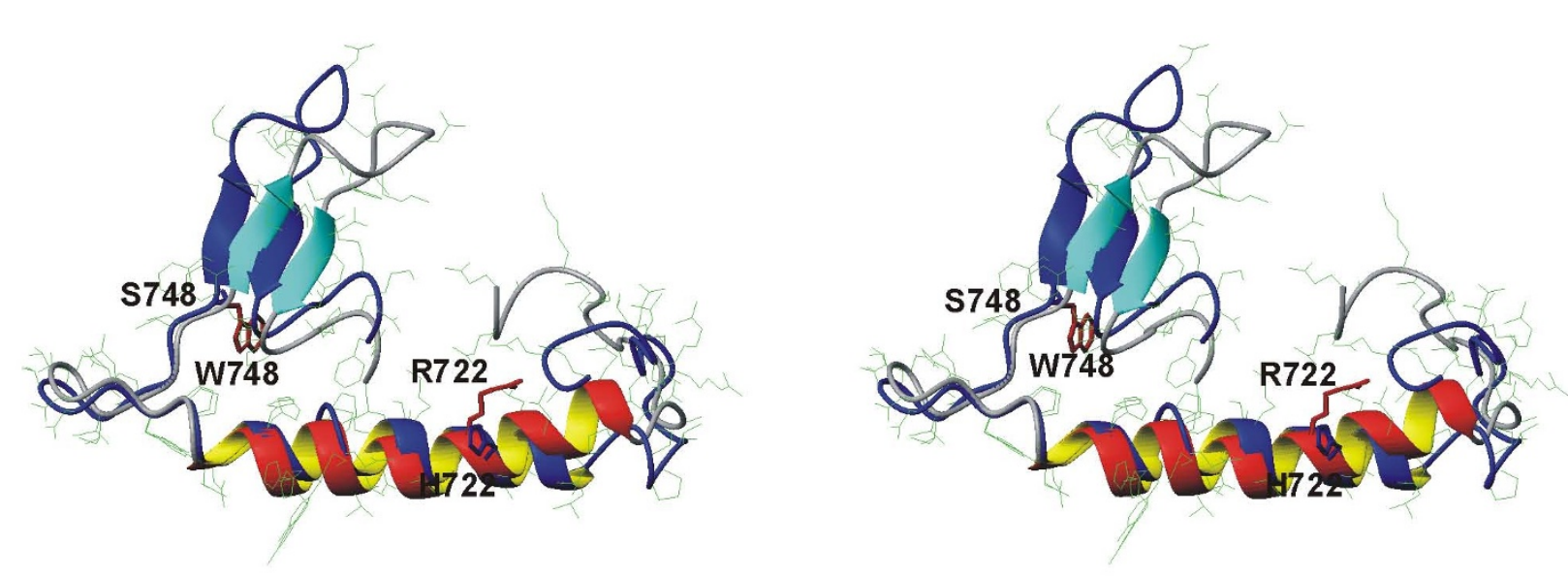

Figure 8 Cartoon of a tentative structure of a segment of the spacer region of human pol $ү A$. Stereo views of the region from residue \#700 to \#770 of the normal (red/gray) and p.R722H/p.W748S double mutant (blue) protein is shown. The structure was predicted with homology modeling by using 1 kln.pdb as a template. p.R722 (red), p.W748 (red), p.H722 (blue) and p.S748 (blue) are highlighted.

drial recessive ataxia syndrome (MIRAS) is typically found in patients with homozygous or compound heterozygous p.W748S POLG1 mutations who present with adult or juvenile-onset ataxia combined with dysarthria, sensory neuropathy, late cognitive impairment, oculomotor defects, myoclonus, tremor, psychiatric symptoms and seizures $[18,29]$. The clinical features of patient B1 and her sister (patient B2) are consistent with the patients harboring compound linker region mutations who have epilepsy, mental retardation and psychiatric symptoms as their presenting features [13,18]. A similar phenotype has also been associated with another heterozygous linker area mutation p.G517V with multiple endocrinopathy, basal lacunar infarcts, seizures, headache and psychiatric disorders as presenting features [30]. Recent observations have suggested a possible dominant effect in p.W748S heterozygotes, since more severe phenotypes and poorer survival have been observed in patients with compound heterozygosity for POLG1 p.W748S compared with patients who are homozygous for this mutation [18].

Both POLG1 mutations, p.R722H and p.W748S, are situated in the linker region which mediates interaction between the polymerase and exonuclease domains, so that mutations might lead to a significant reduction in the enzyme activity in vitro [31]. In vitro studies have also suggested that the p.A467T mutation leads to conformational changes in the catalytic subunit and disrupts binding of the accessory subunit [32]. The p.W748S mutation alone has been shown to cause a catalytic defect involving poor DNA synthesis and primer extension [33], which suggests that the compound p.R722H + p.W748S mutation in POLG1 may lead to dysfunction of the polymerase by alteration of the linker region according to a similar pattern. Although the 3-D structure of subunit-A of the mitochondrial DNA polymerase from higher eukaryotes is not known, the crystal structure of the Klenow fragment (residues 324-928) of E. coli DNA polymerase I has been obtained, even complexed with duplex DNA and at $3.2 \AA$ resolution [34]. Beese et al. [34] propose that DNA enters the polymerase site from the 3 '-exonuclease domain and bends into a cleft. There are a few arginine residues in this cleft domain, and p.R631 in a region which gives a loose match with the human sequence, and its positively charged guanidinium group is in close contact with the phosphodiester backbone of one of the DNA strands [34]. Site-directed mutagenesis of $E$. coli Klenow fragment has shown that a p.R631A mutation leads to a slight decrease in fidelity of the polymerase reaction although the effect was not statistically significant [35]. Although the p.R722 of the eukaryotes is not highly conserved, the presence of arginine in this region may be important. The homologous p.R631 in E. coli is conserved in the Pol I family and located in a domain, which experiences conformational change upon DNA binding. In higher eukaryotes the corresponding "spacer" region shows a high degree of evolutional conservation, suggesting that this region has functional significance. Sitedirected mutagenesis of Drosophila pol $\gamma \mathrm{A}$ has indicated that the linker domain is involved in DNA binding [36]. Loss of the positive charge of arginine in this region may affect template binding and by this means alter its activity or fidelity.

The carrier frequency of p.R722H was 1:135 being as high as that reported for two other POLG1 mutations in the Nordic countries. The carrier frequency of p.W748S is 1:125 in Finland [29] and 1:100 in Norway [13,37], while that of p.A467T is 1:200 in Sweden and in Norway. 


\section{Conclusions}

We found a pathogenic mutation p.R722H in POLG1 in three siblings, who were homozygous for the mutation and presented with a clinical phenotype suggesting a mitochondrial disease. Interestingly, in another family two children were compound heterozygotes with respect to POLG1 p.R722H and p.W748S mutations. The children had mental retardation, ptosis and epilepsy thus resembling the clinical phenotype that has been described in subjects with compound heterozygosity for p.W748S and another POLG1 mutation.

Homology modeling and analysis of the E. coli pol 1 suggest that p.R722 may reside near enough the DNAbinding site to influence the replication fidelity. Although the conservation of p.R722 is not high, it resides in a highly conserved region. The sequence stretch around p.R722 has some homology with a region in pol 1 of $E$. coli having several amino acid residues with charged side chains probably involved in DNA binding.

We suggest that POLG1 p.R722H mutation causes a late-onset neurological phenotype as a homozygous state, whereas the onset of the disease can be earlier in patients with compound heterozygosity for POLG1 p.R722H and other pathogenic POLG1 mutations. Due to the high carrier frequency of POLG1 p.W748S and p.R722H mutations further clinical evaluation of carriers and in vitro functional studies of these mutationswill be worthwhile.

\section{Competing interests}

The authors declare that they have no competing interests.

\section{Authors' contributions}

TK participated the molecular genetic studies and drafted the manuscript. RH and SF participated the molecular genetic studies. $\mathrm{IH}$ carried out sequence analysis and molecular modeling. MK and LP carried out the clinical evaluation of the patients and wrote the patient cases. HT carried out the histological analysis. HR helped to draft the manuscript. KM and JU conceived of the study, participated in its design and coordination and helped to draft the manuscript. All authors read and approved the final manuscript.

\section{Acknowledgements}

The authors thank Ms. Sirpa Miettinen, Ms. Anja Heikkinen and Ms. Pirjo Keränen for their expert assistance. The work was supported by grants from the Research Council for Health at the Academy of Finland (K.M.), the Sigrid Juselius Foundation (K.M.), the Finnish Medical Foundation (J.U), the Arvo and Lea Ylppö Foundation (J.U.), the Finnish Foundation for Pediatric Research (J.U.) and the Alma and K.A. Snellman Foundation (J.U.).

\section{Author Details}

1Department of Pediatrics, University of Oulu, Box 5000, FIN-90014, University of Oulu, Oulu, Finland, 2Department of Neurology, University of Oulu, Box 5000, FIN-90014, University of Oulu, Oulu, Finland, ${ }^{3}$ Department of Clinical Genetics, Oulu University Hospital, Box 5000, FIN-90014, University of Oulu, Oulu, Finland , ${ }^{4}$ Department of Pathology, University of Oulu, Box 5000, FIN-90014, University of Oulu, Oulu, Finland, 5Department of Medical Biochemistry and Molecular Biology, University of Oulu, Box 5000 (Aapistie 7), FIN-90014, University of Oulu, Oulu, Finland and ${ }^{6}$ Clinical Research Center, Oulu University Hospital, Box 5000, FIN-90014, University of Oulu, Oulu, Finland

Received: 29 July 2009 Accepted: 3 May 2010

Published: 3 May 2010

\section{References}

1. Graziewicz MA, Longley MJ, Copeland WC: DNA polymarase $\gamma$ in mitochondrial DNA replication and repair. Chem Rev 2006, 106:383-405

2. Kaguni LS: DNA polymerase $\gamma$, the mitochondrial replicase. Annu Rev Biochem 2004, 73:290-320.

3. Hudson G, Chinnery PF: Mitochondrial DNA polymerase- $\gamma$ and human disease. Hum Mol Genet 2006, 15:244-255

4. Yakubovskaya E, Lukin M, Chen Z, Berriman J, Wall JS, Kobayashi R, Kisker C, Bogenhagen DF: The EM structure of human DNA polymerase $\gamma$ reveals a localized contact between the catalytic and accessory subunits. EMBO J 2007, 26:4283-4291.

5. Horvath R, Hudson G, Ferrari G, Fütterer N, Ahola S, Lamantea E, Prokisch $H$, Lochmüller $H$, McFarland R, Ramesh V, Klopstock T, Freisinger P, Salvi F, Mayr JA, Santer R, Tesarova M, Zeman J, Udd B, Taylor RW, Turnbull D, Hanna M, Fialho D, Suomalainen A, Zeviani M, Chinnery PF: Phenotypic spectrum associated with mutations of the mitochondrial polymerase Y gene. Brain 2006, 129:1674-1684.

6. Longley MJ, Graziewicz MA, Bienstock RJ, Copeland WC: Consequences of mutations in mitochondrial DNA polymerase $\gamma$. Gene 2005, 354:125-131.

7. Van Goethem G, Dermaut B, Löfgren A, Martin JJ, Van Broechoven C: Mutation of POLG is associated with progressive external ophthalmoplegia characterized by mtDNA deletions. Nat Genet 2001, 28:211-212.

8. Lamantea E, Tiranti V, Bordoni A, Toscano A, Bono F, Servidei S, Papadimitriou A, Spelbrink H, Silvestri L, Casari G, Comi GP, Zeviani M: Mutations of mitochondrial DNA polymerase $\gamma A$ are a requent cause of autosomal dominant or recessive progressive external ophtaloplegia. Ann Neurol 2002, 52:211-219.

9. Agostino A, Valletta L, Chinnery PF, Ferrari G, Carrara F, Taylor RW, Schaefer AM, Turnbull DM, Tiranti $\bigvee$, Zeviani M: Mutations of ANT1, Twinkle and POLG1 in sporadic progressive external ophthalmoplegia (PEO). Neurology 2003, 60:1354-1356.

10. Filosto M, Mancuso M, Nishigaki Y, Pancrudo J, Harati Y, Gooch C, Mankodi A, Bayne L, Bonilla E, Shanske S, Hirano M, DiMauro S: Clinical and genetic heterogenity in progressive external ophthalmoplegia due to mutations in polymerase $\gamma$. Arch Neurol 2003, 60:1279-1284.

11. Van Goethem G, Martin JJ, Dermaut B, Löfgren A, Wibail A, Ververken D, Tack P, Dehaene I, Van Zandijcke M, Moonen M, Ceuterick C, De Jonghe P, Van Broeckhoven C: Recessive POLG mutations presenting with sensory and ataxic neuropathy in compund heterozygote patients with progressive external ophthalmoplegia. Neuromuscul Disord 2003, 13:133-142

12. Van Goethem G, Luoma P, Rantamäki M, Al Memar A, Kaakkola S, Hackman P, Krahe R, Löfgren A, Martin JJ, De Jonghe P, Suomalainen A, Udd B, Van Broeckhoven C: POLG mutations in neurodegenerative disorders with ataxia but no muscle involvement. Neurology 2004 63:1251-1257

13. Winterthun S, Ferrari G, He L, Taylor RW, Zeviani M, Turnbull DM, Engelsen $B A$, Moen G, Bindoff LA: Autosomal recessive mitochondrial ataxic syndrome due to mitochondrial polymerase gamma mutations. Neurology 2005, 64:1204-1208.

14. Luoma PT, Eerola J, Ahola S, Hakonen AH, Hellström O, Kivistö KT, Tienari PJ, Suomalainen A: Mitochondrial DNA polymerase gamma variants in idiopathic sporadic Parkinson disease. Neurology 2007, 69:1152-1159.

15. Luoma P, Melberg A, Rinne JO, Kaukonen JA, Nupponen NN, Chalmers RM, Oldfors A, Rautakorpi I, Peltonen L, Majamaa K, Somer H, Suomalainen A: Parkinsonism, premature menopause, and mitochondrial DNA polymerase $\gamma$ mutations: clinical and molecular genetic study. Lancet 2004, 364:875-882.

16. Naviaux RK, Nguyen KV: POLG mutations associated with Alpers' syndrome and mitochondrial DNA depletion. Ann Neurol 2004, 55:706-712.

17. Ferrari G, Lamantea E, Donati A, Filosto M, Briem E, Carrara F, Parini R, Simonati A, Santer R, Zeviani M: Infantile hepatocerebral syndromes associated with mutations in the mitochondrial DNA polymerase- $\gamma \mathrm{A}$. Brain 2005, 128:723-731.

18. Tzoulis C, Engelsen BA, Telstad W, Aasly J, Zeviani M, Winterthun S, Ferrari $G$, Aarseth $J H$, Bindoff $L A$ : The spectrum of clinical disease caused by the A467T and W748S POLG mutations: a study of 26 cases. Brain 2006, 129:1685-1692. 
19. Uusimaa J, Hinttala R, Rantala H, Päivärinta M, Herva R, Röyttä M, Soini H, Moilanen JS, Remes AM, Hassinen IE, Majamaa K: Homozygous W748S mutation in the POLG1 gene in patients with juvenile-onset Alpers' syndrome and status epilepticus. Epilepsia 2008, 49:1038-1045.

20. Schapira AHV: Mitochondrial disease. Lancet 2006, 368:70-82.

21. González-Vioque E, Blázquez A, Fernández-Moreira D, Bornstein B, Bautista J, Arpa J, Navarro C, Campos Y, Fernández-Moreno MA, Garesse R, Arenas J, Martín MA: Association of novel POLG mutations and multiple mitochondrial DNA deletions with variable clinical phenotypes in Spanish population. Arch Neurol 2006, 63:107-111.

22. Copeland WC: Inherited mitochondrial diseases of DNA replication. Annu Rev Med 2008, 59:309-324.

23. Van Goethem G, Martin JJ, Van Broeckhoven C: Progressive external ophtalmoplegia and multiple mitochondrial deletions. Acta Neurol Belg 2002, 102:39-42

24. Remes AM, Majamaa-Voltti K, Kärppä M, Moilanen JS, Uimonen S, Helander H, Rusanen H, Salmela PI, Sorri M, Hassinen IE, Majamaa K: Prevalence of large scale mitochodrial DNA deletions in an adult Finnish population. Neurology 2005, 64:976-981.

25. Cole C, Barber JD, Barton GJ: The Jpred 3 secondary structure prediction server. Nucleic Acids Research 2008, 36(Suppl 2):197-201.

26. Sali A, Blundell TL: Comparative protein modelling by satisfaction of spatial restraints. J Mol Biol 1993, 234:779-815.

27. Koradi R, Billeter M, Wuthrich K: MOLMOL: A program for display and analysis of macromolecular structures. J Mol Graph 1996, 14:51-55. 2932

28. Braasch DA, Corey DR: Locked nucleic acid (LNA): fine-tuning the recognition of DNA and RNA. Chem Biol 2001, 8:1-7.

29. Hakonen AH, Heiskanen S, Juvonen V, Lappalainen I, Luoma PT, Rantamaki M, Goethem GV, Lofgren A, Hackman P, Paetau A, Kaakkola S, Majamaa K, Varilo T, Udd B, Kaariainen H, Bindoff LA, Suomalainen A Mitochondrial DNA polymerase W748S mutation: a common cause of autosomal recessive ataxia with ancient European origin. Am J Hum Genet 2005, 77:430-441

30. Hopkins SE, Somoza A, Gilbert DL: Rare autosomal dominant POLG1 mutation in a family with metabolic strokes, posterior column spinal degeneration, and multi-endocrine disease. J Child Neurol 2009.

31. Luoma PT, Luo N, Löscher WN, Farr CL, Horvath R, Wanschitz J, Kiechl S, Kaguni LS, Suomalainen A: Functional defects due to spacer-region mutations of human mitochondrial DNA polymerase in a family with an ataxia-myopathy syndrome. Hum Mol Genet 2005, 14:1907-1920.

32. Chan SSL, Longley MJ, Copeland WC: The common A467T mutation in the human mitochondrial DNA polymerase (POLG) compromises catalytic efficiency and interaction with the accessory subunit. J Biol Chem 2005, 280:31341-31346.

33. Chan SSL, Longley MJ, Copeland WC: Modulation of the W748S mutation in DNA polymerase $\gamma$ by the E1143G polymorphism in mitochondrial disorders. Hum Mol Genet 2006, 15:3473-3483.

34. Beese LS, Derbyshire V, Steitz TA: Structure of DNA polymerase I Klenow fragment bound to duplex DNA. Science 1993, 260:352-355.

35. Minnick DT, Bebenek K, Osheroff WP, Turner RM Jr, Astatke M, Liu L, Kunkel TA, Joyce CM: Side chains that influence fidelity at the polymerase active site of Escherichia coli DNA polymerase I (Klenow fragment). J Biol Chem 1999, 274:3067-3075.

36. Luo N, Kaguni LS: Mutations in the spacer region of Drosophila mitochondrial DNA polymerase affect DNA binding, processivity, and the balance between Pol and Exo function. J Biol Chem 2005, 280:2491-2497.

37. Kollberg G, Moslemi AR, Darin N, Nennesmo I, Bjarnadottir I, Uvebrant P, Holme E, Melberg A, Tulinius M, Oldfors A: POLG1 mutations associated with progressive encephalopathy in childhood. J Neuropathol Exp Neurol 2006, 65:758-768

\section{Pre-publication history}

The pre-publication history for this paper can be accessed here: http://www.biomedcentral.com/1471-2377/10/29/prepub

doi: $10.1186 / 1471-2377-10-29$

Cite this article as: Komulainen et al., POLG1 p.R722H mutation associated with multiple mtDNA deletions and a neurological phenotype BMC Neurology 2010, 10:29

\section{Submit your next manuscript to BioMed Central} and take full advantage of:

- Convenient online submission

- Thorough peer review

- No space constraints or color figure charges

- Immediate publication on acceptance

- Inclusion in PubMed, CAS, Scopus and Google Scholar

- Research which is freely available for redistribution

Submit your manuscript at www.biomedcentral.com/submit
C Biomed Central 